\title{
NÚCLEO DE SUSTENTABILIDADE E EDUCAÇÃO AMBIENTAL: A ATUAÇÃO DA ENGENHARIA AMBIENTAL NA TRANS-FORMAÇÃO HUMANA
}

\author{
Ana Carolina Borella Marfil Anhê ${ }^{1}$ \\ Bruna Lopes Coêlho ${ }^{2}$ \\ Patrícia Diniz Martins ${ }^{3}$ \\ Ana Luísa Curado 4 \\ Thiago Henrique Barnabé Corrêa ${ }^{5}$ \\ Ana Paula Milla dos Santos Senhuk ${ }^{6}$
}

Resumo: O Núcleo de Sustentabilidade e Educação Ambiental da UFTM visa a aproximação do saber acadêmico com a realidade social, permitindo que a comunidade se beneficie do conhecimento promovido pela universidade na busca por soluções de problemas ambientais. Nesse sentido, tem sido desenvolvidas atividades como arborização, coleta seletiva, compostagem, monitoramento da qualidade da água e do ar e práticas sustentáveis na universidade e em escolas públicas; algumas delas descritas ao longo do artigo. O Núcleo se preocupa em não assumir a EA como receita prescrita, mas como um instrumento de trans-formação humana capaz de gerar impacto social e ambiental, ao incorporar na cultura acadêmica um novo nível de consciência: a consciência ecológica.

Palavras-chave: Consciência Ambiental Ativa; Desenvolvimento Sustentável; Formação Humana.

\footnotetext{
1 Universidade Federal do Triângulo Mineiro. E-mail: ana.anhe@uftm.edu.br

2 Universidade Federal do Triângulo Mineiro. E-mail: bruna.coelho@uftm.edu.br

3 Universidade Federal do Triângulo Mineiro. E-mail: patricia.martins@uftm.edu.br

${ }^{4}$ Universidade Federal do Triângulo Mineiro. E-mail: ana.curado@uftm.edu.br

${ }^{5}$ Universidade Federal do Triângulo Mineiro. E-mail: correa.uftm@gmail.com

${ }^{6}$ Universidade Federal do Triângulo Mineiro. E-mail: ana.senhuk@uftm.edu.br
} 
Abstract: The UFTM's Center for Sustainability and Environmental Education aims to bring academic knowledge closer to social reality, allowing the community to benefit from the knowledge promoted within the university in the search for possible solutions to environmental problems. In this sense, activities such as afforestation, selective collection, composting, monitoring of water and air quality have been developed, in addition to sustainable practices at the university and in public schools in Uberaba; some of them described throughout the article. The Center is concerned with not assuming EE as prescribed recipes, but as an instrument of human transformation capable of generating social and environmental impact by incorporating a new level of awareness in academic culture: ecological awareness.

Keywords: Active Environmental Awareness; Sustainable Development; Human Formation.

\section{Introdução}

No contexto de uma crise ambiental em expansão, com o uso indiscriminado dos recursos naturais, aumento da poluição e das desigualdades sociais, a Educação Ambiental (EA) torna-se essencial para o despertar de uma consciência ambiental ativa e o desenvolvimento de uma nova racionalidade - sustentável -, no sentido em que resgata valores como o respeito à vida e ao meio ambiente (CORRÊA; BARBOSA, 2018).

O final dos anos de 1940 inaugurou grandes movimentos conservacionistas e, com eles, a bandeira da EA a qual tem se consolidado em uma perspectiva pedagógica e de intervenção política, tornando-se, nos dias de hoje, um vasto campo científico e acadêmico (REIGOTA, 2012). Dentre os aproximadamente 70 anos da $E A$, tendo os primeiros registros da utilização do termo no encontro da União Internacional para a Conservação da Natureza UICN (1948), em Paris, os rumos da EA só começam a ser realmente definidos a partir da Conferência de Estocolmo (1972), onde se atribui a inserção da temática da EA na agenda internacional. Posteriormente, com o lançamento do Programa Internacional de Educação Ambiental (1975) em Belgrado - atual Sérvia -, foram definidos os princípios e orientações para o futuro (HENRIQUES et al., 2007).

De acordo com a Constituição Federal Brasileira de 1988 (BRASIL, 1988),

Art. 225. Todos têm direito ao meio ambiente ecologicamente equilibrado, bem de uso comum do povo e essencial à sadia qualidade de vida, impondo-se ao Poder Público e à coletividade o dever de defendê-lo e preservá-lo para as presentes e futuras gerações.

$\S 1^{\circ}$ - Para assegurar a efetividade desse direito, incumbe-se ao Poder Público:

VI- Promover a Educação Ambiental em todos os níveis de ensino e a conscientização pública para a preservação do meio ambiente[...] 
Contudo, sabe-se que uma população consciente dos problemas ambientais não necessariamente irá atuar na busca de soluções e transformações da realidade. Afinal, ter acesso à informação "ecologicamente" correta não significa ter atitudes ambientalmente desejáveis, conforme pontua Chaves e Gaia (2014). Neste sentido, se a EA não permitir uma nova postura de mundo, assim como uma identidade cultural dos indivíduos com as questões que a eles são postas em discussão (SANTOS; SCHNETZLER, 2010), essa não passará de um discurso romancista e utópico. Com isso, a EA segundo Sauvé, (2005, p. 317),

não é simplesmente uma "ferramenta" para a resolução de problemas ou de gestão do meio ambiente. Trata-se de uma dimensão essencial da educação fundamental que diz respeito a uma esfera de interações que está na base do desenvolvimento pessoal e social: a da relação com o meio em que vivemos, com essa "casa de vida" compartilhada.

Em consonância às ideias apresentadas, a Política Nacional de Educação Ambiental define este conceito como "o conjunto de processos por meio dos quais o indivíduo e a coletividade constroem valores sociais, conhecimentos, habilidades, atitudes e competências voltadas para a conservação do meio ambiente (BRASIL, 1999). Tratam-se, então, de ações e práticas educativas em instituições de ensino ou na comunidade, que visam sensibilizar a coletividade acerca das questões ambientais, formando e preparando cidadãos críticos para uma ação social corretiva e transformadora (PHILIPPI JÚNIOR; PELICIONI, 2014).

Para a compreensão das causas socioeconômicas, políticas e culturais geradoras dos problemas ambientais é necessária a interlocução entre diferentes áreas do conhecimento como ciências ambientais, sociais e da saúde. Portanto, a EA não deve ser desenvolvida simplesmente como uma disciplina específica, mas sim em um processo de inserção multidisciplinar em todos os níveis de ensino, incluindo o superior, conforme orientação do Programa Nacional de Educação Ambiental - PNEA (BRASIL, 2018), tornando esse tema transversal ao ensino, à pesquisa e à extensão. Ainda que a EA possa ser um elo de comunicação entre a universidade e a sociedade, nota-se que muitas atividades dessa natureza são desenvolvidas sem o diálogo efetivo entre as partes, o que pouco contribui na construção de sociedades sustentáveis (DORNFELD, 2019).

A sensibilização ecológica e crítica em diferentes públicos e setores da sociedade mundial não pode deixar de envolver também as universidades, que por seu papel assumem uma responsabilidade essencial na formação de novos profissionais (TAUCHEN; BRANDLI, 2006). No entanto, apesar da grande disseminação do tema, a ambientalização no Ensino Superior tem se confrontado com alguns desafios. Segundo Jacobi, Raufflet e Arruda (2011), 
um desses desafios que é que a maioria das IES tem dado um enfoque fragmentado para a EA e a sustentabilidade, adicionando muitas vezes conteúdo sobre meio ambiente a uma parte específica do currículo. Outro desafio é a resistência encontrada na promoção da interdisciplinaridade como uma condição para a educação visando a sustentabilidade, o que ocorre não apenas por razões administrativas, mas também pela relutância dos docentes, formados em uma visão disciplinar, de se engajarem com abordagens mais práticas e extensionistas (Experiencial Learning). Diante da necessidade de uma mudança profunda e duradoura no processo organizacional dentro das instituições, o Ensino Superior deve abordar a sustentabilidade de forma mais sistêmica, que envolva toda a instituição nas mudanças em andamento, em colaboração com estratégias de aprendizagem (JACOBI; RAUFFLET; ARRUDA, 2011).

Nesse contexto, o Núcleo de Sustentabilidade e Educação Ambiental da Universidade Federal do Triângulo Mineiro (UFTM) foi criado em 2016, a princípio com o objetivo de divulgar os projetos de extensão que vinham sendo realizados por docentes do Departamento de Engenharia Ambiental, mas que foi tomando uma amplitude multidisciplinar em suas ações. Desde março de 2018, o Núcleo está cadastrado como Sala Verde no Ministério do Meio Ambiente e vem divulgando suas atividades na plataforma do mesmo (http://salasverdes.mma.gov.br/), além do site próprio (https://educacaoambiental.wixsite.com/nucleouniverde), em eventos no município e pelo setor de comunicação da UFTM. Sua criação corrobora às metas estabelecidas pelo Plano de Desenvolvimento Institucional da UFTM (PDI), como o fortalecimento das atividades e cursos de extensão universitária oferecidos à comunidade interna e externa. Assim, são objetivos do Núcleo: i) realizar atividades de EA com a comunidade acadêmica, contribuindo para a maior ambientalização no Ensino Superior e sustentabilidade da UFTM; ii) envolver alunos dos cursos de Engenharia, em especial da Engenharia Ambiental, e da Pós-Graduação em Ciência e Tecnologia Ambiental em atividades extensionistas de EA; iii) divulgar as pesquisas na área de Ciências Ambientais realizadas por graduandos e mestrandos, às escolas públicas, com uma linguagem mais acessível; e, iv) despertar o interesse da sociedade para a problemática ambiental, na identificação de problemas e busca por soluções.

O Núcleo visa alcançar seus objetivos a partir de parcerias com profissionais das ciências sociais e da saúde, do setor público e privado, abordando temas ambientais de forma prática, lúdica, multidisciplinar e transversal. Assim, este texto compartilha algumas experiências promissoras do Núcleo e seus fundamentos.

\section{Atividades desenvolvidas com a comunidade acadêmica}

Os cursos de Engenharias da UFTM possuem em seus Projetos Pedagógicos disciplinas que abordam questões ambientais logo no primeiro ano, e estão estruturados na visão de indissociabilidade entre ensino, pesquisa e extensão. Contudo, há a necessidade de medidas que melhorem as práticas 
sustentáveis no campus. Nesse sentido, desde 2015 tem sido desenvolvidas atividades como arborização, coleta seletiva, compostagem e práticas sustentáveis na Unidade Univerdecidade, do campus Uberaba (Figura 1).
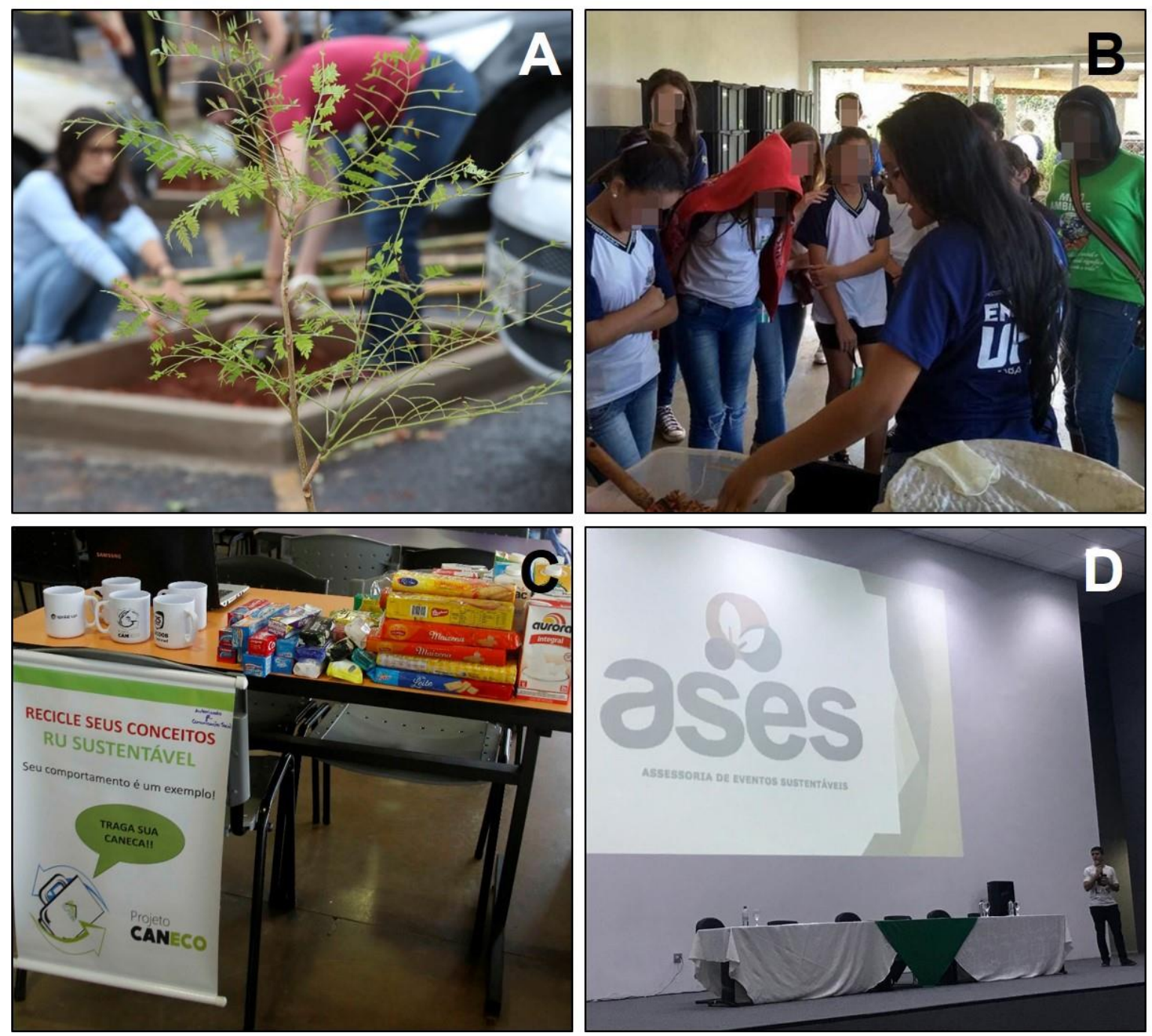

Figura 1: Atividades de EA com a comunidade acadêmica. A: Arborização da Unidade Univerdecidade/UFTM. B: Projeto Recicla UFTM, Lab. de Vermicompostagem. C: Projeto CanEco. D: Assessoria de Eventos Sustentáveis (ASES)

Fonte: Autoria própria.

\section{1 - Arborização da Univerdecidade (Figura 1A)}

O projeto tem como objetivo mobilizar a comunidade acadêmica quanto à necessidade de ampliar a área verde do campus com árvores frutíferas, para paisagismo e sombreamento nos estacionamentos, criando ambientes mais agradáveis para convívio dos alunos em atividades extraclasse e, podendo contribuir indiretamente para a diminuição da taxa de evasão. O plantio de mudas tem sido realizado a cada ano no período chuvoso e em ocasiões especiais como no ingresso de alunos da graduação e da pós-graduação, Empresa Júnior de Engenharia Ambiental e Núcleo de Empreendedorismo, em 
Semanas Acadêmicas e outros eventos na universidade. Também foram realizados plantios esporádicos com estudantes do ensino básico da rede municipal de Uberaba em comemoração ao Dia da Árvore e com o grupo de escoteiros mirins. A manutenção das mudas (estaqueamento, rega, adubação, controle de pragas e poda) tem sido realizada principalmente por graduandos em Engenharia Ambiental.

Em cinco anos de desenvolvimento do projeto, já foram plantadas mais de 2.000 mudas de árvores de pequeno, médio e grande porte. $O$ trabalho voluntário da equipe e a colaboração dos funcionários da limpeza e jardinagem tem sido crucial para a sobrevivência de praticamente todas as mudas plantadas desde o início do projeto. Os espaços criados com a construção de canteiros e bancos têm sido amplamente utilizados, e outros cursos começaram a plantar árvores também, mostrando que o projeto tem motivado de certa forma toda a comunidade acadêmica.

\section{2 - Recicla UFTM (Figura 1B)}

O programa Recicla UFTM foi criado em 2014 e tem como objetivo atuar no gerenciamento dos resíduos sólidos descartados no Univerdecidade da UFTM, promovendo a coleta seletiva desses resíduos, sua quantificação e destinação ambientalmente adequada. A coleta é realizada por segregação na fonte, em coletores dispostos em locais estratégicos. Anualmente, o programa coleta:

- cerca de 2,5 toneladas de resíduos recicláveis, formados por plásticos, papéis, papelão, latas e vidros. Destaca-se que 1 tonelada corresponde a papel branco, formado por provas e documentos sigilosos que são fragmentados antes do descarte. Todo o material é doado à Cooperativa de Reciclagem de Uberaba, que busca semanalmente os resíduos na universidade. Os coletores estão dispostos em locais variados no campus, como biblioteca, pátio próximo à cantina, sala dos professores e secretarias. Como coletores são utilizados tambores de 200 litros nas áreas externas e caixas de papelão nas áreas internas, todos devidamente identificados.

- cerca de 1,2 toneladas de resíduos orgânicos formados por cascas de frutas, restos de verduras e legumes oriundos do preparo das refeições no Restaurante Universitário $(\mathrm{RU})$ e da sobra dos pratos. Os resíduos são diariamente coletados em lixeiras de coleta seletiva instaladas na cozinha e no salão onde as refeições são servidas e encaminhados à vermicompostagem. Trata-se de um sistema de caixas sobrepostas onde minhocas californianas aceleram o processo de decomposição dos resíduos. O sistema produz cerca de 900 litros de adubo líquido e 500 litros de adubo sólido, húmus que são destinados ao projeto de arborização (PADOVAN et al., 2019).

- cerca de 500 pilhas/baterias usadas, oriundas das atividades da universidade e da comunidade, destinadas ao sistema de logística reversa. Para os 
coletores, são utilizadas embalagens plásticas de 5 litros identificadas. Eles estão localizados próximas aos coletores de coleta seletiva.

- cerca de 400 litros de óleo residual de fritura que são trocados por produto de limpeza em uma empresa privada. Os coletores são tambores plásticos de 200 litros onde as garrafas PET contendo óleo são devidamente dispostas.

Atividades de EA tem sido realizadas com a comunidade universitária, visando maior adesão ao programa com a segregação correta dos resíduos, além da comunidade externa, com visitas guiadas ao Laboratório de Vermicompostagem durante eventos como as Semanas Acadêmicas, Feira de Profissões, Dia C da Ciência, I Mostra de Trabalhos em Ciência e Tecnologia Ambiental, dentre outros. As redes sociais também são utilizadas para divulgação das atividades do programa, o qual recebeu financiamento da Pró Reitoria de Extensão (PROEXT) da UFTM para aquisição de materiais de consumo, permanentes e bolsas para os alunos.

Além de reduzir a quantidade de resíduos sólidos enviada ao aterro sanitário, a ação contribui diretamente para a sustentabilidade e para a sensibilização da comunidade quanto à importância de pequenas atitudes na busca da redução dos impactos/problemas ambientais.

\section{3 - Projeto CanEco (Figura 1C)}

O projeto CanEco tem o objetivo de incentivar a substituição de copos descartáveis por canecas reutilizáveis no RU da Unidade Univerdecidade da UFTM. Desde o ano de 2015 o projeto vem amadurecendo e ganhando adesão cada vez maior da comunidade acadêmica. Inicialmente foi feito um levantamento quantitativo de uso de copos no RU, o qual indicou uma média de 500 copos descartados diariamente. Em pesquisa de opinião, o índice de aceitação da substituição desses por canecas foi de $93 \%$. Em vista disso, a equipe do projeto solicitou aos Centros Acadêmicos das Engenharias a inserção de canecas reutilizáveis nos "kits" oferecidos aos calouros ingressantes de 2015.

Nos anos seguintes, o projeto de substituição de copos descartáveis por canecas teve andamento com promoção de campanhas para estímulo e cooperação, com divulgação de informações em eventos da universidade, promoção de rodas acadêmicas sobre o tema, divulgação no site institucional e desenvolvimento de material informativo sobre impactos ambientais advindos do descarte de materiais plásticos. A proposta atual é que a substituição seja feita de forma gradativa, até que esse material não seja mais distribuído pelo $\mathrm{RU}$, diminuindo seu descarte até a sua total eliminação.

Em 2018 o projeto recebeu financiamento da Pró-Reitoria de Extensão (PROEXT) da UFTM para compra de canecas reutilizáveis; outras canecas foram doadas por patrocinadores que inseriram suas logomarcas nas mesmas. Foram distribuídas cerca de 100 canecas, as quais foram trocadas por alimentos não perecíveis e itens de higiene pessoal, doados para associações

revista brasileira educação ambiental 
de voluntários de hospitais localizados em Uberaba, divulgando assim o projeto e promovendo uma ação social. Em 2019, foram doadas, aproximadamente, 500 canecas para os ingressantes dos cursos de engenharias e de licenciaturas da Instituição. Apesar da promoção da mudança de hábito não ser uma tarefa simples, o projeto tem proporcionado uma interação transformadora entre a universidade e outros setores da sociedade, sensibilizando integrantes da comunidade externa e interna quanto à preservação ambiental e ajudando pessoas carentes de recursos financeiros.

Quando relacionamos práticas sustentáveis com universidades públicas, soma-se o fato de que a administração pública tem promovido discussões sobre a adoção dessas práticas em seus órgãos por meio de dispositivos legais e diretrizes específicas como, por exemplo, o Plano de Logística Sustentável PLS (BRASIL, 2012). Tendo em vista os benefícios para o meio ambiente e o bem-estar da comunidade acadêmica, a UFTM vem implementando em suas unidades práticas que reduzam sua geração de resíduos. Portanto, além dos efeitos positivos que a substituição dos copos descartáveis proporciona, esse projeto se insere no escopo do PLS da UFTM e vem contribuir para a mudança de hábitos que o citado Plano propõe.

\section{4 - Assessoria de Eventos Sustentáveis (ASES) (Figura 1D)}

A realização de eventos é responsável por uma série de benefícios para os destinos onde são empreendidos; no entanto, há geração de impactos ambientais negativos, como aumento no consumo de água, energia e materiais utilizados, que resultam em resíduos, além da emissão de gases que contribuem com o efeito estufa pelo uso de veículos para deslocamento dos participantes. Nesse sentido, a utilização de práticas adequadas pode potencializar os benefícios para as partes interessadas dos eventos. Por meio de um planejamento eficiente é possível trabalhar pela conservação do meio, o que proporciona um legado positivo para o lugar em que foi realizado e incentiva a sensibilização e mudança de hábitos entre os participantes do evento (PRESBURY; EDWARDS, 2005; PICCIN; DOWEL, 2011).

Conforme dados do setor de Comunicação Social, a UFTM promove cerca de 400 eventos por ano, de semanas acadêmicas a congressos regionais. Explorando a grande quantidade de eventos que são realizados na universidade, aliado à geração de resíduos e impactos ambientais decorrentes de sua realização, foi desenvolvido um projeto de extensão visando promover a inserção de práticas sustentáveis nesse setor. O projeto é realizado desde 2014, quando foi elaborado o Guia de Eventos Sustentáveis da UFTM (GALDINO; COÊLHO, 2015), no qual foram descritas práticas para que fossem inseridos critérios de sustentabilidade no planejamento e execução de eventos vinculados à universidade. Com o objetivo de facilitar a busca pelas práticas sustentáveis desejadas, o Guia é composto por onze tópicos distribuídos em um quadro, que versam sobre diferentes maneiras de reduzir impactos negativos no planejamento e execução dos eventos; são eles: comissão 
organizadora do evento; patrocínio; divulgação e inscrição; acessibilidade; hospedagem; consumo de água e energia; resíduos sólidos; materiais utilizados; transporte; alimentação; e serviços de limpeza.

Uma vez que o Guia apoia um desenvolvimento sustentável nos eventos, além da preocupação com a degradação do meio ambiente, também aborda práticas que incentivam a inclusão social e práticas que geram uma redução no gasto monetário. No aspecto social, sugere que as comissões disponibilizem informações sobre rotas de transporte público, bicicletário, opções de alimentação diferenciada de acordo com as necessidades dos participantes, taxas diferenciadas de inscrição e acessibilidade a portadores de necessidades especiais. $\mathrm{Na}$ dimensão econômica, orienta recorrer a patrocinadores, reduzir a divulgação impressa, possibilitar inscrições eletrônicas, evitar desperdícios nos materiais disponibilizados aos participantes e na decoração do ambiente.

Nos anos subsequentes foram formadas equipes discentes com a função de assessorar esses eventos, tornando mais efetiva a execução das práticas propostas pelo Guia. Criada em 2015, a equipe foi denominada Assessoria de Eventos Sustentáveis (Ases) e tem seus membros renovados anualmente. Pela falta de referências relacionadas a esse tipo de atividade, a assessoria de eventos sustentáveis foi uma inovação na UFTM (NEVES; COÉLHO, 2019). Em 2015 e 2016 foram 37 eventos assessorados no total, sendo $5 \%$ classificados como "Não sustentáveis", 68\% como "Parcialmente Sustentáveis" e 27\% como "Sustentáveis". De 2017 a 2019, dos 18 eventos assessorados, somente 1 recebeu classificação intermediária, enquanto 17 foram considerados como "Sustentáveis" pela pontuação obtida na tabela do Guia.

Apesar de certa resistência inicial da comunidade acadêmica em aceitar a assessoria, motivada pela falta de conscientização socioambiental e preocupação com aumento de gastos, o projeto tem ganhado maior aceitação, mostrando-se eficiente em influenciar as comissões quanto ao uso de práticas sustentáveis, como adoção de pastas feitas com banner reaproveitado, substituição de copos descartáveis por canecas duráveis, realização dos eventos em locais com acessibilidade e inserção de comidas veganas (NEVES; COÊLHO, 2019).

\section{Atividades desenvolvidas com estudantes do Ensino Básico}

Uma das metas do Núcleo é prover, através da EA, a aproximação do saber acadêmico com a realidade social, permitindo que a população se beneficie do conhecimento promovido pelas atividades realizadas pela universidade, estimulando a compreensão sobre os problemas ambientais locais e envolvendo-a na busca por possíveis soluções, a partir de uma visão holística. 
Conforme defendem Corrêa e Barbosa (2018), o espaço escolar é, para muitas crianças, o primeiro lugar de contato real com boas práticas ambientais, de conscientização e responsabilidade socioambiental, o que revela a urgência do educar para a cidadania, no sentido de atuar no e sobre o meio, tendo a escola um papel importante, mas não exclusivo, no processo de formação de seres reflexivos. Com isso, segundo o referido autor, a EA deixa de ser algo a ser transmitido, mas, sobretudo, conquistado. Nesse sentido, desde 2014 o Núcleo tem atuado em escolas municipais e estaduais de Uberaba em atividades de EA, conforme alguns projetos descritos a seguir (Figura 2).
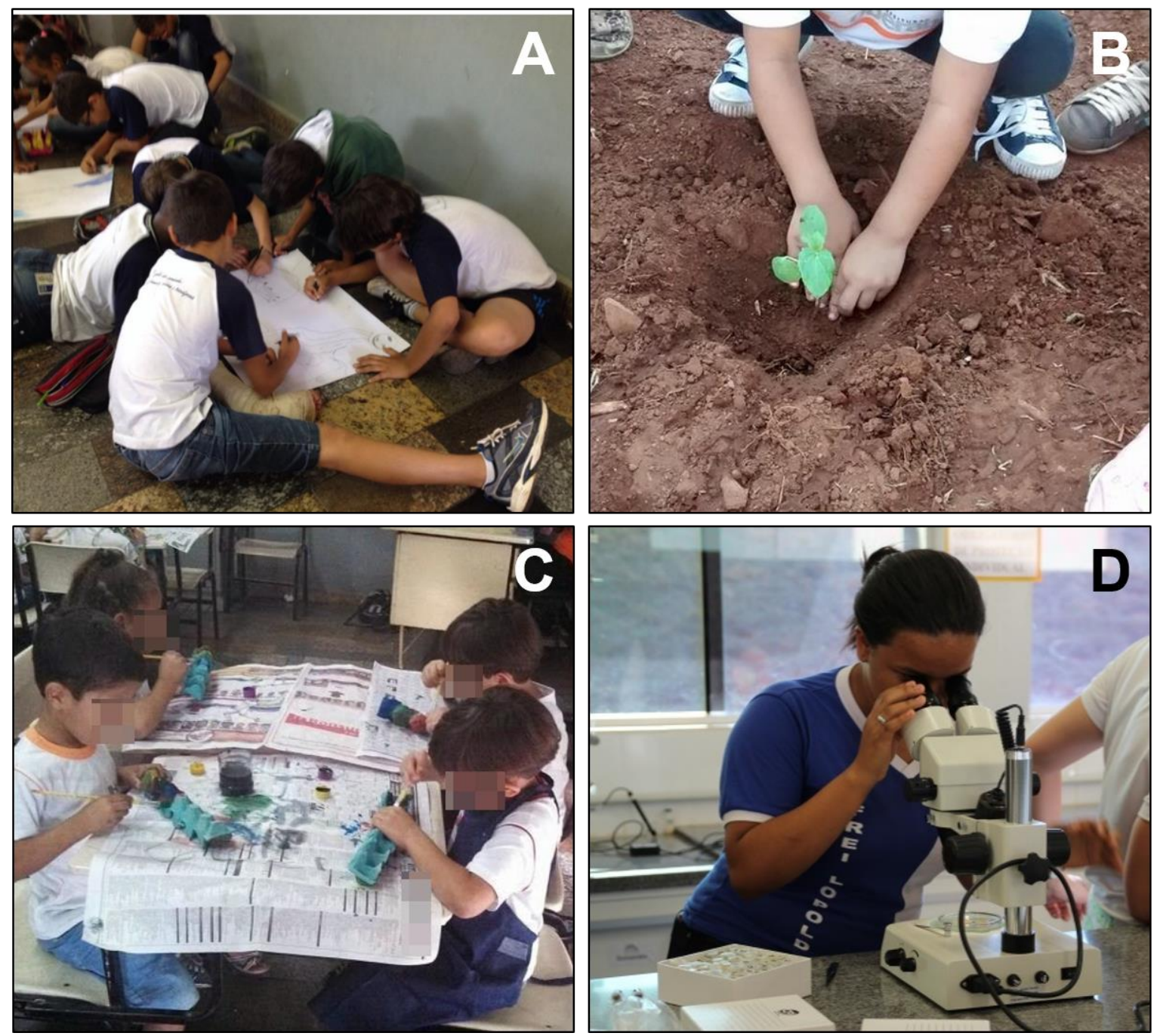

Figura 2: Atividades em escolas municipais e estaduais de Uberaba. A: Oficinas de Educação Ambiental. B: Arborização de um Centro Municipal de Educação Infantil. C: Produção de brinquedos com material reciclável. D: Biomonitoramento da água por meio de macroinvertebrados bentônicos.

Fonte: Autoria própria. 


\section{1 - Oficinas de Educação Ambiental (Figura 2A)}

A geração de resíduos é um dos problemas mais agravantes da sociedade contemporânea e sua disposição inadequada contribui para a degradação ambiental. Assim, fica claro que a falta de sensibilização da sociedade é um fator agravante para essa questão. Nesse contexto, a EA infantil é importante, pois é nesta fase do aprendizado que a criança começa a interagir com a sociedade e a adquirir valores. Dessa forma, o objetivo principal do projeto foi ensinar a cultura do reaproveitamento de materiais por meio da reutilização e reciclagem, sensibilizando as crianças da escola quanto à preservação da natureza. O projeto foi realizado com 120 crianças, de 6 a 9 anos de uma escola estadual da cidade de Uberaba.

Antes de iniciar as atividades práticas das oficinas, um questionário foi enviado aos pais das crianças, sobre os temas coleta seletiva, separação de resíduos, compostagem, entre outros, a fim de conhecer as necessidades da comunidade e orientar as atividades que seriam realizadas. Um dos focos das atividades do projeto foi estimular a curiosidade das crianças sobre o principal assunto abordado: resíduos sólidos urbanos. Dentro dele trabalhou-se, por meio de oficinas práticas, o conhecimento sobre de onde vêm e o que acontece com os resíduos provenientes de produtos de nosso cotidiano. O ciclo das atividades foi disposto de forma que, a cada duas semanas, seis salas eram atendidas por três duplas de alunos, durante o ano letivo. Foram realizadas as seguintes atividades: jogo de memória educativo sobre reciclagem; compostagem de resíduos orgânicos; apresentação de dois documentários infantis sobre resíduos; colheita das hortaliças; montagem das "Resíduas" (lixeiras para coleta seletiva); discussão sobre a cadeia de produção de PET, vidro, metal e papel; prática da reciclagem de papel; e criação de jardim vertical no pátio da escola.

As atividades possibilitaram uma melhor compreensão sobre o tema abordado por todos os envolvidos no projeto, ou seja, crianças, professores, diretores e discentes, utilizando-se do princípio de que quanto mais cedo a questão ambiental for apresentada à criança, mais cedo ela começará a valorizá-la.

\section{2 - Educação Ambiental sobre Poluição do ar e Saúde Infantil (Figura 2B)}

A poluição atmosférica é uma importante questão de saúde pública em centros urbanos, por trazer consequências ao meio ambiente e à saúde da população, principalmente de idosos e crianças (FAROKHI; HEEDERIK; SMIT, 2018). Dessa forma, o objetivo do projeto foi analisar a concentração de material particulado $\left(\mathrm{MP}_{10}\right)$ e o quadro de doenças respiratórias em crianças de 5 Centros Municipais de Educação Infantil (CEMEI) de Uberaba, comparando os resultados com a distância da rodovia.

Os CEMEls foram escolhidos de acordo com a distância da BR-050, sendo o CEMEI A: 50 m ao Norte da rodovia; B: 400 m ao Norte; C: 900 m ao 
Norte, D: $850 \mathrm{~m}$ a Oeste e, E: $3000 \mathrm{~m}$ ao Norte. Um questionário baseado no International Study of Asthma and Allergies in Childhood (ISAAC) foi distribuído para 40 alunos em cada CEMEI, juntamente com o Termo de Consentimento Livre e Esclarecido (TCLE), para ser assinado pelos pais ou responsáveis que desejassem participar do estudo (Projeto aprovado pelo Comitê de Ética em Pesquisa, no 54412216.0.0000.5154). Realizou-se o estudo com alunos de quatro a cinco anos de idade pelo fato de doenças alérgicas serem agravadas no período de inicialização no ambiente escolar, em que há maior exposição às infecções respiratórias. A concentração de material particulado $\left(\mathrm{MP}_{10}\right)$ foi avaliada por três dias não-consecutivos em cada CEMEI, por meio do monitor portátil de partículas DUSTTRAK II - TSI 8530.

O projeto contou com a devolução de $78 \%$ dos 200 questionários entregues. Sintomas respiratórios como chiado no peito, tosse seca à noite, expectoração, dificuldade para respirar, espirro, corriza, lacrimejamento ou coceira nos olhos, sem a criança estar gripada, foram mais frequentes no período de maio a setembro em todos os CEMEls. Nesses meses mais secos, o aumento do número de inversões térmicas, juntamente com a baixa umidade relativa do ar, agrava a ação irritativa dos poluentes ambientais sobre o trato respiratório da criança (NICOLUSSI et al., 2014; WHO, 2018).

As concentrações máximas de $\mathrm{MP}_{10}$, acima do limite permitido (150 $\mu \mathrm{g} / \mathrm{m}^{3}$ ) pelos padrões nacionais de qualidade do ar (CONAMA, 1990, CONAMA, 2018), foram registradas nos CEMEls A $\left(193 \mu \mathrm{g} / \mathrm{m}^{3}\right)$ e $D(356$ $\left.\mu \mathrm{g} / \mathrm{m}^{3}\right)$. A variação da concentração de poluentes do ar nos pontos deste estudo pode estar relacionada à direção e à velocidade dos ventos nos dias de coleta de dados. Além da distância da rodovia, esses parâmetros ambientais também precisam ser avaliados em estudos futuros.

Os resultados foram divulgados para todos os CEMEls e o material disponibilizado para os educadores trabalharem a questão da poluição do ar e saúde com as crianças. Durante o estudo, foi levantada a necessidade de desenvolver alguma ação ambiental na escola mais próxima da rodovia, CEMEI A (a $50 \mathrm{~m}$ de distância). Após reuniões com a direção da escola e com a Secretaria Municipal de Educação de Uberaba, foi desenvolvido um projeto paisagístico que consistiu em plantar árvores na calçada e no contorno de toda a escola (cerca-viva), além de árvores frutíferas no quintal, jardim vertical e horta, com o uso de material reciclado como pneus e pallets de madeira.

O projeto incentivou o desenvolvimento de atividades de EA com as crianças e o engajamento de funcionários pela questão ambiental abordada, melhorando a segurança, pela menor visibilidade da escola com a cerca-viva, além de contribuir para a diminuição de ruído e criação de uma barreira verde para mitigação da poluição do ar. 


\section{3 - Educação Ambiental de crianças utilizando como ferramenta o desenvolvimento de composteira e horta (Figura 2C)}

A maioria dos valores que temos quando adultos são aprendidos na infância. Nesta etapa da vida é importante que os ensinamentos que visam à sustentabilidade também sejam aprendidos, em diferentes espaços, para que os adultos do futuro consigam criar uma interação harmônica entre o "progresso" e natureza. Um fator importante para a preservação do meio ambiente é a reciclagem, seja ela de resíduos orgânicos ou não. Assim, o objetivo do projeto foi ensinar a cultura do reaproveitamento de materiais, sensibilizando as crianças quanto à preservação da natureza, e propor a criação de uma horta, apresentando a importância das hortaliças na alimentação e incentivando hábitos alimentares saudáveis.

Foram utilizadas oficinas de reciclagem, reutilização e plantio com a participação de 120 crianças de cinco a nove anos de uma escola municipal. As crianças confeccionaram porta lápis e brinquedos a partir de garrafas PET, caixas Tetra Pak, cilindros de papelão e caixas de ovos. Garrafas PET e pneus também foram pintados e utilizados para o plantio de flores na escola. Os materiais reciclados utilizados foram coletados na escola e no campus da UFTM, incentivando a coleta seletiva e a reciclagem. A horta teve início com o plantio de hortaliças e árvores frutíferas pelas crianças, que acompanharam a manutenção semanalmente até a colheita. Dessa forma, o projeto buscou incentivar uma consciência ecológica e hábitos alimentares saudáveis de todos os envolvidos, incluindo as crianças, pais e funcionários. O projeto foi financiado pela PROEXT-UFTM.

\section{4 - Biomonitoramento da saúde de ecossistemas aquáticos por meio de macroinvertebrados bentônicos (Figura 2D)}

Os ecossistemas aquáticos são impactados pelo lançamento de efluentes industriais e domésticos, além do uso inadequado do solo. Tendo em vista sua preservação, torna-se necessário o monitoramento desses ecossistemas, utilizando além da avaliação físico-química, indicadores biológicos, a fim de determinar a qualidade da água medida pelas alterações estruturais e funcionais das comunidades de organismos aquáticos (BUSS; BAPTISTA; NESSIMIAN, 2003).

Por meio de atividades de campo e no laboratório, foram coletados, triados e identificados macroinvertebrados bentônicos como bioindicadores da qualidade da água do rio Uberaba e afluentes. Além disso, foram realizados encontros para discussão de temas como meio ambiente e poluição, com enfoque na saúde ambiental de ecossistemas aquáticos, autodepuração de corpos d'água e o uso de bioindicadores para monitoramento aquático. Também foram apresentados os cursos de Engenharia da UFTM, as formas de assistência estudantil disponibilizadas pela universidade, além de pesquisas sobre o perfil dos alunos do Ensino Médio sobre a intenção de cursar Engenharia na UFTM.

revista brasileira educação ambiental 
O Projeto foi executado tendo como público alvo:

- alunas do Ensino Médio de uma escola estadual, a fim de despertar o interesse para a área de Engenharia Ambiental e mais especificamente sobre a questão da saúde ambiental de ecossistemas aquáticos, permitindo a identificação de potenciais fontes de poluição da água e o conhecimento de metodologias de biomonitoramento;

- ingressante do curso de Engenharia Ambiental da UFTM, a fim de combater a evasão que ocorre principalmente nos primeiros anos do Ensino Superior, despertando o interesse da graduanda pelo aprimoramento de sua formação acadêmica, científica e tecnológica e pelo desenvolvimento de trabalho no campo e no laboratório.

O projeto foi aprovado pelo Edital MCTI/CNPq/SPM-PR/Petrobras no 18/2013, incluindo 4 bolsas para estudantes participantes e 1 para o professor da rede pública, que acompanhou as atividades.

\section{Conclusões}

Frente ao exposto, espera-se que os resultados atuais e a longo prazo das atividades do Núcleo contribuam para a construção de uma sociedade mais sustentável e sensível às questões ambientais, servindo de exemplo para outras IES que reconhecem seu papel na defesa de uma nova, urgente e necessária ecologia social. Embora muitos não foram formados em um modelo que utilizasse a extensão como agente transformador (humano e da realidade humana), precisamos interpelar o nosso "ser" formador sobre a responsabilidade social que nos é confiada (CORRÊA, 2019).

Espera-se, ainda, que a atuação do Núcleo possa contribuir como estratégia de divulgação e popularização da Ciência, assim como para o desenvolvimento científico e tecnológico do País, aproximando alunos da rede pública de ensino, IES e comunidade, possibilitando a troca de experiência e conhecimentos sobre temas relacionados ao meio ambiente e criando um ambiente favorável à formação de profissionais conscientes de seu papel na sociedade. É nessa perspectiva que o Núcleo busca atuar como "mediador" entre pessoas que representam o futuro e o meio ambiente, construindo valores sustentáveis, formando opiniões e promovendo uma visão crítica e responsável de mundo, de modo a educar para transformar a consciência e permitir aos envolvidos vivenciar, experimentar e compreender aspectos e a totalidade de seu mundo [interior e exterior] (CHAVES; GAIA, 2014; CORRÊA; BARBOSA, 2018).

Vale pontuar que o Núcleo concebe a EA sob uma perspectiva extensionista. Em outras palavras, como um instrumento de trans-formação humana capaz de gerar impacto social e ambiental, seja no contexto local ou mais amplo. Assim, torna-se preocupação das ações desenvolvidas pela equipe não assumir a EA como receitas prescritas e/ou impositivas, mas como prática de reflexão e diálogo, além de ser objeto de pesquisa e significação do conteúdo a ser ensinado na universidade.

Revbea, São Paulo, V. 15, № 5: 365-380, 2020. 


\section{Referências}

BRASIL. Constituição da República Federativa do Brasil de 5 de outubro de 1988.

Disponível

em:

$<$ http:///www.planalto.gov.br/ccivil 03/constituicao/constituicao.htm>. Acesso em: 09 out. 2019.

BRASIL. Lei 9.795 de 27 de abril de 1999. Dispõe sobre a Educação Ambiental, institui a Política Nacional de Educação Ambiental. Disponível em: $<$ http://www.planalto.gov.br/ccivil 03/Leis/L9795.htm>. Acesso: 09 out. 2019.

BRASIL. Instrução Normativa $\mathbf{n}^{\circ} \mathbf{1 0}$ de 12 de novembro de 2012. Estabelece regras para elaboração dos Planos de Gestão de Logística Sustentável. Disponível em: $<$ http://www.lex.com.br/legis 23960118 INSTRUCAO NORMATIVA N 10 DE 12>. Acesso em: 09 out. 2019.

BRASIL. Ministério do Meio Ambiente. Educação Ambiental para um Brasil Sustentável: Pronea, marcos legais e normativos. $5^{\underline{a}}$ ed. Brasília-DF: MMA, 2018. 104p.

BUSS, D.F.; BAPTISTA, D.F.; NESSIMIAN, J.L. Bases conceituais para a aplicação de biomonitoramento em programas de avaliação da qualidade da água de rios. Cadernos de Saúde Pública, v. 19, n. 2, p. 465-473, 2003.

CHAVES, R.A.; GAIA, M.C.M. O papel da escola na construção da Educação Ambiental: ações e reflexões. Revista da SBEnBIO, v. 7, p. 6356-6368, 2014.

CONAMA. Conselho Nacional do Meio Ambiente. Resolução no 03 de 28 de junho de 1990. Dispõe sobre padrões de qualidade do ar, previstos no PRONAR. Disponível em: <http://www.ibram.df.gov.br/images/resol 03.pdf>. Acesso em: 09 out. 2019.

CONAMA. Conselho Nacional do Meio Ambiente. Resolução no 491 de 19 de novembro de 2018. Dispõe sobre padrões de qualidade do ar. Disponível em: $<$ http://www2.mma.gov.br/port/conama/legiabre.cfm?codlegi=740>. Acesso em: 09 out. 2019.

CORRÊA, T.H.B. Diálogo e alteridade: a extensão na transversalidade do ensino superior. Revista Triângulo, v. 12, n. 1, 2019.

CORRÊA, T.H.B.; BARBOSA, N.A.P. Educação Ambiental e consciência planetária: uma necessidade formativa. Revista eletrônica do Mestrado em Educação Ambiental, v. 35, p. 125-136, 2018.

DORNFELD, C.B. Educação Ambiental: reflexões e desafios no Ensino Superior. Rede Viva Melhor - Resumo Executivo. Ilha Solteira-SP: UNESP. Disponível em: <https://www.foar.unesp.br/Home/projetoviverbem/educacaoambiental-reflexoes-e-desafios-no-ensino-superior---resumo.pdf $>$. Acesso em: 10 nov. 2019. 
FAROKHI, A.; HEEDERIK, D.; SMIT, L.A.M. Respiratory health effects of exposure to low levels of airborne endotoxin - a systematic review. Environmental Health, v. 17, n. 14, 2018.

GALDINO, G.V.; COÊLHO, B.L. Guia de Eventos Sustentáveis. 1a ed. Uberaba-MG: UFTM, 2015. 27p.

HENRIQUES, R. et al. Educação Ambiental: aprendizes de sustentabilidade. Cadernos SECAD 1. Brasília: MEC, 2007. 109p.

JACOBI, P.R.; RAUFFLET, E.; ARRUDA, M.P.A educação para a sustentabilidade nos cursos de Administração: reflexão sobre paradigmas e práticas. Revista de Administração Mackenzie, v. 12, n. 3, p. 21-50, 2011.

NEVES, L.A.L.; COÊLHO, B.L. Assessoria para inclusão de práticas sustentáveis em eventos da Universidade Federal do Triângulo Mineiro. Revista Em Extensão, v. 18, n.1, p. 34-62, 2019.

NICOLUSSI, F.H. et al. Poluição do ar e doenças respiratórias alérgicas em escolares. Revista de Saúde Pública, v. 48, n. 2, p. 326-30, 2014.

PADOVAN, C. et al. Vermicompostagem de resíduos orgânicos: relato de experiência em Educação Ambiental. Educação Ambiental em Ação, n. 69, 2019.

PICCIN, A.C.; DOWELL, D.M. Eventos mais sustentáveis. In: MATIAS, M. (Coord.) Planejamento, Organização e sustentabilidade em eventos: Culturais, sociais e esportivos. São Paulo-SP: Manole Conteúdo, 2011.

PHILIPPI JÚNIOR, A.; PELICIONI, M.C.F. Educação Ambiental e Sustentabilidade. $2^{\mathrm{a}}$ ed. Barueri-SP: Manole, 2014. 1024p.

PRESBURY, R.; EDWARDS, D. Incorporating sustainability in meetings and event management education. International Journal of Event Management Research, v. 1, n. 1, p. 30-45, 2005.

REIGOTA, M. Educação Ambiental: a emergência de um campo científico. Perspectiva, v. 30, n. 2, p. 499-520, 2012.

SANTOS, W.L.P.; SCHNETZLER, R.P. Educação em Química: compromisso com a cidadania. ljuí: Ed. UNIJUÍ, 2010.

SAUVÉ, L. Educação Ambiental: possibilidades e limitações. Educação e Pesquisa, v. 31, n. 2, p. 317-322, 2005.

TAUCHEN, J.; BRANDLI, L.L. A gestão ambiental em instituições de ensino superior: modelo para implantação em campus universitário. Revista Gestão e Produção, v. 13, n. 3, p. 503-515, 2006.

WHO. World Health Organization. Ambient (outdoor) air quality and health, 2018. Disponível em: <http://www.who.int/mediacentre/factsheets/fs313/en/>. Acesso em:15 jun. 2019. 